\title{
Knowledge, Attitude and Practice toward Infant Oral Healthcare among the Pediatricians of Mysore: A Questionnaire Survey
}

\author{
${ }^{1} \mathrm{MD}$ Indira, ${ }^{2}$ Kanika Singh Dhull, ${ }^{3} \mathrm{~B}$ Nandlal
}

\begin{abstract}
Background: The aim of this study was to study the knowledge, attitude and practice of the pediatricians toward infant oral healthcare and the objective was to determine what can improve the knowledge, attitude and practice toward infant oral healthcare.
\end{abstract}

Materials and methods: A systematic random survey of pediatricians in Mysore received a questionnaire pertaining to individual details, knowledge level and approach toward infant oral healthcare.

Results: Most of pediatricians acknowledged the importance of pediatric dentistry. Pediatricians agree that it is important to do dental examination before 1 year. The importance of initiating oral hygiene practice before the eruption of first tooth was not seen to be prevalent among the pediatricians. Most of them were less aware of the first dental visit including early childhood caries (ECC). All pediatricians agree that both medical and dental professionals together are responsible for infant oral healthcare. They should work together to appropriately educate and train themselves to be able to provide risk assessment and to provide preventive oral health services.

Keywords: Infant oral healthcare, Pediatricians, Preventive dentistry.

How to cite this article: Indira MD, Dhull KS, Nandlal B. Knowledge, Attitude and Practice toward Infant Oral Healthcare among the Pediatricians of Mysore: A Questionnaire Survey. Int J Clin Pediatr Dent 2015;8(3):211-214.

Source of support: Nil

Conflict of interest: None declared

\section{INTRODUCTION}

Early childhood caries (ECC) is the most prevalent infectious disease and major threat to oral health in infants and children as reported by center for disease control

\footnotetext{
${ }^{1}$ Senior Lecturer, ${ }^{2}$ Reader, ${ }^{3}$ Professor

1,3 Department of Pedodontics and Preventive Dentistry, JSS Dental College, JSS University, Mysore, Karnataka, India

${ }^{2}$ Department of Pedodontics and Preventive Dentistry, Kalinga Institute of Dental Sciences, Bhubaneswar, Odisha, India

Corresponding Author: Kanika Singh Dhull, Reader, Department of Pedodontics and Preventive Dentistry, Kalinga Institute of Dental Sciences, Bhubaneswar, Odisha, India, Phone: 919439362211, e-mail: kanikasingh.dhull@gmail.com
}

and prevention and the National institute of health. ${ }^{1}$ Early childhood caries and the more severe form of ECC (S-ECC) are particularly virulent forms of caries, beginning soon after tooth eruption; developing on smooth surfaces, progressing rapidly, and having a lasting detrimental impact on the dentition. ${ }^{2}$ It is a lifestyle disease with the biological, behavioral and social discriminates. American Academy of Pediatrics Dentistry (AAPD) recognizes that ECC emerges in all the cultural and economic pediatric population. ${ }^{3}$ Alhough ECC is preventable, more than $50 \%$ of the children have caries by the time they reach the kindergarten. ${ }^{4}$

In 1986, American Academy of Pediatric Dentistry adopted guidelines on infant oral health as a way to promote oral health and prevent oral disease in very young children. ${ }^{5}$ The 25th anniversary of this AAPD policy statement offers an opportunity to rededicate ourselves and increase our efforts to assure equity of oral health for all the children. ${ }^{6}$ Indian Society of Pediatric and Preventive Dentistry (ISPPD) also strives to achieve this goal with the motto 'every child has the fundamental right to his/her total oral health.' ${ }^{7}$ The AAPD recognizes that infant oral health is one of the foundations upon which preventive education and dental care must be built, to enhance the opportunity for a lifetime free from preventable oral disease. It proposes recommendations for preventive strategies, oral health risk assessment, anticipatory guidance and therapeutic interventions to be followed by dental, medical, nursing, and allied health professional programs. ${ }^{8}$ It also states that dentalcaries risk assessment, based on a child's age, biological factors, protective factors, and clinical findings, should be a routine component of periodic examinations by oral health and medical providers. ${ }^{9}$

Promotion of oral health and preventive dental care are fundamental concepts in pediatric dentistry. Today, pediatric dentistry possess a body of scientific knowledge and technology to assist parents in raising caries-free children. An early screening of children below 1 year of age is an excellent opportunity for the detection of risk factors. The goal is to provide infants and toddlers with a pleasant, non-threatening introduction to dentistry 
and to establish and reinforce the foundation for sound dental habits. There is a need to move away from the surgical approach of managing oral diseases and embrace the concept of oral care beginning at infancy or even prenatally.

Since children less than 3 years are not seen routinely by the dentist, they are at risk of developing dental disease. Pediatricians who see a child from birth as part of well baby visit program are in the best position to identify early dental problems and to educate the parents about the early oral preventive healthcare. They also can provide screening services for early detection of dental disease, provide advice about the need to seek dental care and refer those children in need to pediatric dentist. A key element of comprehensive care for children thus involves the coordination of services between medical and dental providers so that they can provide appropriate services at the appropriate ages.

One of the factors which affect the performance of preventive dentistry is the knowledge, attitude and practice of the pediatrician concerning this issue. Basic questions about the delivary of infant oral healthcare, dental referral process and its outcomes remain unanswered. Thus, the present study is designed with the objective to gather the data and evaluate the level of knowledge, attitude and practice toward infant oral healthcare among the pediatricians.

\section{MATERIALS AND METHODS}

The present survey was undertaken among the pediatricians of Mysore, as listed in the Indian Academy of Pediatrics (IAP), Mysore chapter A comprehensive questionnaire was prepared based on the studies done by Tegwyn et al, Prakash et al and Murthy et al. ${ }^{10-12}$

The questionnaire contained 27 questions. To check the reliability and validity of the questionnaire, a pilot study was done among 10 pediatricians. The results obtained were subjected to statistical analysis. Cronbach's alpha value of 0.84 showed a good internal consistency of the questionnaire. After the questions were considered to be reliable, it was handed over personally to all the pediatricians who agreed to participate in the survey. The questionnaire was collected after 1 day. The results obtained were analyzed using statistical package for social science (SPSS) software descriptive and inferential statistical tests.

\section{RESULTS}

Among a total of 120 pediatricians as listed in the IAP, Mysore chapter, 97 of them completed the questionnaire, giving the response rate of $80.83 \%$. The results of the study are tabulated and discussed.

\section{DISCUSSION}

The IAP Mysore chapter lists 120 pediatricians, 97 of which responded for the study giving a very good response rate of $80.83 \%$. It is a common agreement amongst AAPD, AAP and ADA that early dental screening is the key to improve infant oral healthcare and prevent ECC. ${ }^{8,13,14}$ The allied healthcare professionals and community organizations must involve and collaborate to achieve this goal. Research study shows that the pediatricians are not advising patients to see the dentist by 1 year of age. ${ }^{14,15}$

Traditionally, AAP had recommended seeing the dentist by the age of 36 months. However, more recently the AAP has changed and expanded its oral health guidelines; and the recent policy aims to establish a dental home for children by 1 year of age through the use of oral health risk assessment at 6 months of age. The policy recommends referring a child for oral health examination within 6 months of eruption of first primary tooth but not later than 12 months of age. The policy also focuses on the specific preventive strategies like diet counseling, optimal use of fluoride and providing anticipatory guidance. ${ }^{13}$ Infant oral healthcare awareness with regard to ECC, oral hygiene practice and specialty treatment to infants rendered by the pediatricians is unclear. Hence, this study was undertaken to know the awareness, attitude and practice of pediatricians toward infant oral healthcare.

Table 1 shows the demographic data of the pediatricians surveyed. Out of the pediatricians surveyed, $67 \%$ were males and $33 \%$ were females. Since the responses of the questionnaire are qualitative; the correct responses were given a quantitative value and mean score was calculated. The mean score was found to be higher in practitioners with $\geq 10$ years of experience as compared to those with $<10$ years of practice. The difference in mean score between them was found to be statistically significant $(\mathrm{p}<0.001)$, suggesting that pediatrician with more experience had better knowledge toward infant oral healthcare (Table 1A).

Table 1: Demographic information of the respondents

\begin{tabular}{|c|c|c|c|c|c|c|}
\hline \multirow[b]{3}{*}{ Gender } & \multicolumn{4}{|c|}{ Years of experience } & \multirow{2}{*}{\multicolumn{2}{|c|}{ Total }} \\
\hline & \multicolumn{2}{|c|}{$<10$ years } & \multicolumn{2}{|c|}{$\geq 10$ years } & & \\
\hline & $N$ & $\%$ & $n$ & $\%$ & $n$ & $\%$ \\
\hline Male & 37 & 60 & 28 & 80 & 65 & 67 \\
\hline Female & 25 & 40 & 7 & 20 & 32 & 33 \\
\hline Total & 62 & 100 & 35 & 100 & 97 & 100 \\
\hline
\end{tabular}

Table 1A: Total mean score based on years of experience

\begin{tabular}{lllllll}
\hline $\begin{array}{l}\text { Experience } \\
\text { (years) }\end{array}$ & $n$ & Mean & $\begin{array}{l}\text { Std. } \\
\text { dev. }\end{array}$ & $\begin{array}{l}\text { Mean } \\
\text { difference }\end{array}$ & $t$ & $p$-value \\
\hline$<10$ & 62 & 13.18 & 3.52 & -2.937 & -3.924 & $<0.001^{*}$ \\
$\geq 10$ & 35 & 16.11 & 3.57 & & & \\
\hline
\end{tabular}


All the pediatricians are aware about dentist but only $52 \%$ of them refer. Although $93.8 \%$ of the pediatricians were aware about the pediatric dentistry as specialty, only $48 \%$ referred to pediatric dentist (Table 2). The shortage of pediatric dentists might be the cause for nonreferral. According to the 2011 census, the population of children aged 0 to 6 years in Mysore is 77,988; giving a child to pediatric dentist ratio of 1:3,900, which is quite alarming. ${ }^{16}$ More than $60 \%$ of pediatricians in this study were observed to have adequate knowledge about number of primary teeth and age of first tooth eruption (Table 3).

About $77 \%$ of pediatricians examine the infants' oral cavity at birth. Although $82 \%$ of pediatricians agree that it is important to do dental examination before 1 year, only $43 \%$ of them were aware of the AAPD/AAP recommended first dental visit, and only $11 \%$ advised the parents for child's first dental visit before 1 year of age (Table 4). This could be because many of them are not familiar with recent AAPD/AAP recommendations for pediatric preventive dental care. Some of the pediatricians even question the referral for infants, because previously AAP recommended first dental visit at the age of 36 months. With the increasing incidence of ECC and demand for the total healthcare right from the birth, it is absolutely necessary for the first dental visit below 1 year of age.

The importance of initiating oral hygiene practice before the eruption of first tooth was not seen to be prevalent among the pediatricians. Only $26 \%$ of them recommended to clean the oral cavity from the time of birth after every feed and $47 \%$ of the pediatricians recommended to clean the teeth using toothbrush and paste only after all the primary teeth erupt (Table 5).

In the US, $98.9 \%$ of pediatricians frequently examine a child for signs of dental caries. ${ }^{4}$ In our study, it was found that though $77 \%$ of the pediatricians were aware of pediatric dentistry as specialty and the dental problems associated with infants like eruption cyst, Bohn's nodules and ECC, only $48 \%$ of them referred to pediatric dentist (Table 1). Present study revealed that the pediatricians were aware of the factors causing ECC. In all, $94 \%$ of

Table 2: Pediatricians' awareness about dentistry and its specialty branches

\begin{tabular}{|c|c|c|}
\hline Awareness about dentistry & $97(100 \%)$ & \\
\hline $\begin{array}{l}\text { Awareness about pediatric } \\
\text { dentistry as specialty }\end{array}$ & $91(93.8 \%)$ & \\
\hline $\begin{array}{l}\text { Referral to pediatric } 47(48 \%) \\
\text { dentist }\end{array}$ & Referral to dentist & $50(52 \%)$ \\
\hline
\end{tabular}

Table 3: Pediatricians' awareness about primary dentition

\begin{tabular}{|c|c|c|c|c|}
\hline $\begin{array}{l}\text { Number of } \\
\text { primary teeth }\end{array}$ & $18(12 \%)$ & $20(69 \%)$ & $28(15 \%)$ & $\begin{array}{l}\text { No response } \\
18(12 \%)\end{array}$ \\
\hline $\begin{array}{l}\text { Age of first } \\
\text { tooth eruption } \\
\text { (months) }\end{array}$ & $\begin{array}{l}4-6 \\
(32 \%)\end{array}$ & $\begin{array}{l}6-9 \\
(60 \%)\end{array}$ & $\begin{array}{l}9-12 \\
(8 \%)\end{array}$ & $\begin{array}{l}\text { No response } \\
(0 \%)\end{array}$ \\
\hline
\end{tabular}

the pediatricians examine ECC in infants and $88 \%$ of them discuss about ECC with parents. Though 95\% of the pediatricians say 'no to bottle feeding', only $75 \%$ of pediatricians agreed that bottle feeding leads to ECC; and if the child has to be bottle fed at night, $61 \%$ of pediatricians advise plain water over milk with sugar. However, $71 \%$ of the pediatricians disagree to the fact that even prolonged breastfeeding at night can also lead to ECC. Alhough $95 \%$ of pediatricians agree that nutritional counseling is an important aspect of infant oral health care to prevent ECC, only $33 \%$ of them implement in their practice (Table 6)

Most of the children under 1 year of age are not routinely seen by the dentist, but pediatricians encounter them at least five times before the child is 1 year old. ${ }^{17}$ Hence, pediatricians are in the position to provide information about oral healthcare to parents and make referral to the dentist when required. Studies have shown that if proper awareness is created among pediatricians, they

Table 4: Pediatricians' awareness about first dental visit

\begin{tabular}{|c|c|c|c|c|}
\hline $\begin{array}{l}\text { AAP/AAPD } \\
\text { recommended } \\
\text { age for first } \\
\text { dental visit }\end{array}$ & $\begin{array}{l}\text { At birth } \\
(15 \%)\end{array}$ & $\begin{array}{l}\text { After the } \\
\text { eruption of } \\
\text { first primary } \\
\text { teeth } \\
(43 \%)\end{array}$ & $\begin{array}{l}\text { After the } \\
\text { eruption of } \\
\text { all primary } \\
\text { teeth } \\
(18 \%)\end{array}$ & $\begin{array}{l}\text { No } \\
\text { response } \\
(24 \%)\end{array}$ \\
\hline $\begin{array}{l}\text { It is important } \\
\text { to do dental } \\
\text { examination } \\
\text { for children } \\
<1 \text { year }\end{array}$ & $\begin{array}{l}\text { Disagree } \\
5(5 \%)\end{array}$ & $\begin{array}{l}\text { Neither } \\
\text { agree nor } \\
\text { disagree } \\
13(13 \%)\end{array}$ & $\begin{array}{l}\text { Agree } \\
79(82 \%)\end{array}$ & \\
\hline $\begin{array}{l}\text { Advise parents } \\
\text { for the 1st } \\
\text { dental visit }\end{array}$ & $\begin{array}{l}\text { Never } \\
14 \\
(14 \%)\end{array}$ & $\begin{array}{l}\text { Occasionally/ } \\
\text { Sometimes } \\
72(75 \%)\end{array}$ & $\begin{array}{l}\text { Almost } \\
\text { every time } \\
11(11 \%)\end{array}$ & \\
\hline $\begin{array}{l}\text { Examination of } \\
\text { oral cavity of } \\
\text { infants at birth }\end{array}$ & $\begin{array}{l}\text { Rarely } \\
2(2 \%)\end{array}$ & $\begin{array}{l}\text { Sometimes } \\
10(10 \%)\end{array}$ & $\begin{array}{l}\text { Often } \\
10(10 \%)\end{array}$ & $\begin{array}{l}\text { Always } \\
75 \\
(77 \%)\end{array}$ \\
\hline
\end{tabular}

Table 5: Recommendation of oral hygiene practice for infants

\begin{tabular}{|c|c|c|c|c|}
\hline $\begin{array}{l}\text { Initiation of } \\
\text { cleaning of } \\
\text { oral cavity }\end{array}$ & $\begin{array}{l}\text { From the } \\
\text { time of } \\
\text { birth after } \\
\text { every feed } \\
(26 \%)\end{array}$ & $\begin{array}{l}\text { When the } \\
\text { first tooth } \\
\text { erupts } \\
(45 \%)\end{array}$ & $\begin{array}{l}\text { After all the } \\
\text { primary teeth } \\
\text { erupts } \\
(22 \%)\end{array}$ & $\begin{array}{l}\text { No } \\
\text { response } \\
(7 \%)\end{array}$ \\
\hline $\begin{array}{l}\text { Use of } \\
\text { tooth paste } \\
\text { and brush } \\
\text { to clean the } \\
\text { teeth }\end{array}$ & $\begin{array}{l}\text { When the } \\
\text { first tooth } \\
\text { erupts } \\
(28 \%)\end{array}$ & $\begin{array}{l}\text { After all } \\
\text { the primary } \\
\text { teeth erupt } \\
(47 \%)\end{array}$ & $\begin{array}{l}\text { After } 5 \text { years } \\
\text { of age } \\
(10 \%)\end{array}$ & $\begin{array}{l}\text { No } \\
\text { response } \\
(14 \%)\end{array}$ \\
\hline
\end{tabular}

Table 6: Awareness, attitude and practice toward ECC in infants

\begin{tabular}{lll}
\hline Do you advise bottle feeding for infants & Yes & No \\
& $5(5 \%)$ & $92(95 \%)$ \\
Do you exam ECC in infants & Yes & No \\
& $91(94 \%)$ & $6(6 \%)$ \\
Do you discuss ECC with parents & Yes & No \\
& $85(88 \%)$ & $12(12 \%)$ \\
\hline & & contd...
\end{tabular}


contd...

\begin{tabular}{lll}
\hline If bottle fed at night, contents & Plain water & Sweetened wate \\
advised in the bottle & $59(61 \%)$ & $2(2 \%)$ \\
Bottle feeding at night leads & Strongly disagree & Disagree \\
to dental caries & $0(0 \%)$ & $6(6 \%)$ \\
Prolonged breastfeeding & Strongly disagree & Disagree \\
leads to dental caries & $32(33 \%)$ & $37(38 \%)$ \\
Is nutritional counseling to & Never & Rarely \\
prevent ECC offered in your & $2(2 \%)$ & $21(22 \%)$ \\
practice? & & \\
Type of nutritional counseling & Reduce high & Reduce high \\
given to prevent ECC & sugar snacks & drinks \\
& $22(23 \%)$ & $20(21 \%)$ \\
Nutritional counseling is an & Strongly disagree & Disagree \\
important aspect of infant & $1(1 \%)$ & $2(2 \%)$ \\
oral healthcare to prevent & & \\
ECC & & \\
\hline & & \\
\multicolumn{2}{c}{ Table 7: Who is responsible for infant oral healthcare? } \\
\hline Pediatrician & 0 & \\
Pediatric dentist & $1(1 \%)$ & \\
Both & $96(99 \%)$ & \\
\hline
\end{tabular}

can educate the parents and accurately identify patients in need of referral. ${ }^{4}$ In the present study, $99 \%$ of the pediatricians agreed that both medical and dental professionals together are responsible for infant oral healthcare (Table 7). They should work together to appropriately educate and train themselves to be able to provide risk assessment and preventive oral health services.

\section{Limitations of the Study}

Like any other survey, our study had also certain limitations. Since the study was a close ended questionnaire survey, we were unable to obtain their complete awareness on infant oral healthcare. This study was limited to the group of pediatricians to one area and is not representative of the country. Also, the study did not directly address the barrier to access infant oral healthcare.

\section{CONCLUSION}

From this study it can be concluded that majority of the pediatrician are not advising parents to visit dentist by 1 year of age. Many pediatricians feel that knowledge imparted in medical schools is inadequate as far as infant oral health is concerned. There is a need to educate everyone on infant oral healthcare by conducting regular health educative programs. More interactions between the pediatricians and pediatric dentist would be worth to handle the infant population and provide them complete overall health.

\section{REFERENCES}

1. US Department of Health and Human Services. Oral health in America: Report of surgeon general. NIH publication 2000;00-4713.

2. Nowak AJ, Warren JJ. Infant oral health and oral habits. Pediatr Clin North Am 2000;47(5):1043-1066.

3. Organizational principles to guide and define the child health care system and/or improve the health of all children section on pediatric dentistry oral health risk assessment timing and establishment of the dental home. Pediatrics 2003;111: 1113-1116.

4. Pierce KM, Rozier RG, Vann WF. Accuracy of pediatric primary care providers'screening and referral for early childhood caries. Pediatrics 2002;109(5);e82.

5. American academy of pediatric dentistry. Clinical guidelines on Infant Oral Health Care. Pediatr Dent 1986;8:114-118.

6. Nowak AJ .Celebrate but Rededicate AAPD infant oral health care guidelines-are we ready to celebrate? Pediatr Dent: 2011;33(1):7-8.

7. Available from: www.isppd.org.

8. American academy of pediatric dentistry. Clinical guidelines. Guideline on Infant Oral Health Care. Pediatr Dent Reference manual 36(614/15):141-145.

9. American academy of pediatric dentistry. Reference manual: Guideline on caries-risk assessment and management for infants, children and adolescents. Pediatr Dent 2013:35(5):E157.

10. Brickhouse TH, Unkel JH, Kancitis I, Bes AM. Infant oral healthcare: a survey of general dentists, pediatric dentists, and pediatricians in Virginia. Pediatr Dent 2008;30:147-153.

11. Prakash P, Lawrence HP, Harvey BJ, McIsaac WJ, Limeback H, Leake JL. Early childhood caries and infant oral health: Paediatricians' and family physicians' knowledge, practices and training. Paediatr Child Health 2006;11(3):151-157.

12. Murthy GA, Mohandas U. The knowledge, attitude and practice in prevention of dental caries amongst pediatricians in Bengaluru: A cross-sectional study. J Indian Soc Pedod Prev Dent 2010;2(2)8:100-103.

13. Section on Pediatric Dentistry Preventive Oral Health Intervention for Pediatricians. Pediatrics 2008;122(6):1387-1394.

14. Edelstein BL, Manski RJ, Moeller JF. Pediatric visits during 1996: an analysis of the Federal Medical Expenditure Panel Survey. Pediatr Dent 2000;22(1):17-20.

15. Ismail AI, Nainar SM , Sohn W. Children's first dental visit: attitudes of the practices of US pediatricians and family physicians. Pediatr Dent 2003;25(5):425-430.

16. Available at: $w w w . c e n s u s 2011$.co.in $>$ districtlist $>$ Mysore.

17. Nowak AJ, Casamassimo PS. Using anticipatory guidance to provide early dental intervention. J Am Dent Assoc 1995;126(8):1156-1163. 